\title{
Electronic health record and blockchain architecture: forensic chain hypothesis for human identification
}

\author{
E. Nuzzolese(1)
}

\begin{abstract}
Background: Forensic dental identification relies on the collection and comparison of antemortem and postmortem dental data and dental evidence. There are software solutions capable of archiving postmortem (PM) and antemortem (AM) data, with search and comparative tools which are user-centric and do not allow open search options and data mining of all dental related data, except through the use of coded data. This reduces interoperability and raises dental data incompatibility challenges. Blockchain technology could help introduce a trusted, secure, and holistic ecosystem in the electronic health record (EHR) system with a forensic interface accessed by experts in forensic pathology and forensic odontology for the purpose of identifying human remains and retrieve identifying data of compatible missing persons from the health and dental electronic record system, with the further advantage of protecting data breaches, redundancies, inconsistencies, and errors. Blockchain technology, and a forensic chain, can enhance forensic data management and human identification process by managing the missing person lists, create AM data repositories as shared data with the EHRs of living individuals, create PM data repositories of recovered from identifying autopsies unidentified persons, and support the preliminary comparison of compatible biological profiles during the final reconciliation phase.
\end{abstract}

Conclusion: In this hypothesis, author investigates possible applications of blockchain technology as a holistic technical and interoperability solution for managing both health/dental data for a medical as forensic human identification use.

Keywords: Blockchain technology, Electronic health record, Forensic chain, Forensic data management, Human identification, Missing persons, Forensic odontology

\section{Background}

The identification of unknown human remains relies on comparison of primary identifiers, namely fingerprints, DNA, and dental data, with the equivalent data collected of compatible reported missing persons profiles. Forensic odontology offers the most timely and efficacious biometric method for identifying decomposed, carbonized, skeletonized, and fragmented human remains (Interpol 2018) and has proved to be an effective identification method

Correspondence: emilio.nuzzolese@unito.it

Medico-legal Institute, Department of Public Health Sciences and Pediatrics, University of Turin, Corso Galileo Galilei 22, 10121 Turin, Italy with the overall ID rate of over 83\% in South-East Asia Tsunami (Schuller-Götzburg and Suchanek 2007). Forensic dental identification analyses and compares documentation from oral health professionals of the patients reported missing with the dental data collected in the dental autopsy of the unidentified remains (Silver and Souviron 2009). The procedures to reconcile antemortem and postmortem information have been outlined by numerous forensic organizations including the American Board of Forensic Odontology (ABFO) and British Association of Forensic Odontology (BAFO), as well as many others. The antemortem dental data includes all historical 
dental data and dental evidence collected by dental professionals, dental technicians' laboratories, and families of the missing persons, including old dental devices, radiographs, and portrait pictures or selfies showing frontal teeth (Nuzzolese et al. 2018). The postmortem dental data is the result of the dental autopsy collection including the full periapical $x$-ray images of jaws and dental arches. In some cases, personal identification is performed as a direct comparison of postmortem (PM) with the antemortem (AM) dental records of compatible individuals. Nevertheless, the high number of reported missing persons and unidentified human remains of unknown nationalities raises concerns on the forensic data management and the need of archiving, processing, and comparative analysis of PM and AM dental data, which can benefit from software and IT solutions, as archive and data mining and comparison (Hofmeister et al. 2017; Alsalamah and Nuzzolese 2020).

This paper presents blockchain technology and what it can offer in terms of bridging the gap between missing persons, health/dental data history, dignified management of the dead (Morgan et al. 2006), and human identification process, in conjunction with the development of information and communication technologies at regional, national, and global levels. The improvement acknowledged by the World Health Organization (WHO 2018) in the prioritization of eHealth through digital technologies can strengthen public health resilience also incorporating forensic services by allowing access and sharing of medical/dental data in response to personal identification issues. Blockchain technology can enhance data protection issues such as data access, mining, sharing, security, privacy, and global interoperability.

\section{Presentation of the hypothesis}

One of the fundamentals of any human identification process is the collection of AM data of the missing persons from the families and next-of-kin of the missing, the collection of PM identifying data of recovered human remains and the comparison of AM and PM compatible data, thus achieving a positive ID applying matching or exclusion criteria (Senn and Weems 2013). When considering a human identification process, the most relevant information used to identify human remains come from a patient's health history which is or will be eventually available in his electronic health record (EHR), depending on the countries and the stage of implementations of this system (Kruse et al. 2018). Countries are investing in the EHR system in order to improve health care productivity and efficiency, reduce data costs health management and services (Häyrinen et al. 2008), and share more easily data between all healthcare providers and health organizations. This will lead to a shift from paper-based forms to electronic ones to facilitate digital storage and sharing. Similar to healthcare industry, also the forensic human identification process relies on the collection and exchange of sensitive date, coming from the missing and unidentified persons' profiles. The conceptual basis is to create a patient health record and an unidentified person record composed of data blocks, which contain health datasets and X-ray dataset as well as other identifying features dataset, which can represent valuable secondary identifiers. Blockchain technology, proposed to serve as backbone of Bitcoins (Nakamoto 2008), offers an appropriate solution to this architecture model. A blockchain-based architecture for EHRs (Beinke et al. 2019; Mayer et al. 2019) can become a trusted, secure, and holistic ecosystem in which forensic pathologists and odontologists will be able to retrieve a variety of identifying information, which would then be considered AM data, such as surgical treatments following traumas, diagnostic images (Xrays, TC scans), and dental treatments. A possible use case scenario has been designed using UML tools, illustrated in Fig. 1. In this hypothesis, the interoperability and data maintenance would have the following generic architecture:

- Archive of patient's personal information and medical/dental history records, compiled by patients, medical doctors, and dentists. Data is organized hierarchically and is distributed in chained data blocks; healthcare organizations can access to patient health data blocks through a specific component.

- Archive of missing persons information, compiled by missing persons families and law enforcement agencies and missing persons organizations

- Archive of post mortem data collected during autopsies of unidentified human remains, compiled by forensic pathologists and odontologists. Findings are encrypted and distributed in chained blocks.

- A software component used to perform the input and the output gateway and mining of data blocks for the preliminary human identification process, accessed by forensic scientists, disaster victim identification (DVI) specialists, and law enforcement agencies

\section{Testing the hypothesis}

There are many types of blockchain systems in the literature. The most of blockchain applications beyond cryptocurrency are focused on government services, healthcare delivery, Internet of Things applications, and supply chain management (Al-Megren et al. 2018). Several developers and researchers have conceptualized and implemented blockchain-based platforms with the purpose of sharing patient health data (Hylock and Zeng 2019), designed mainly as patient-centered solutions. 


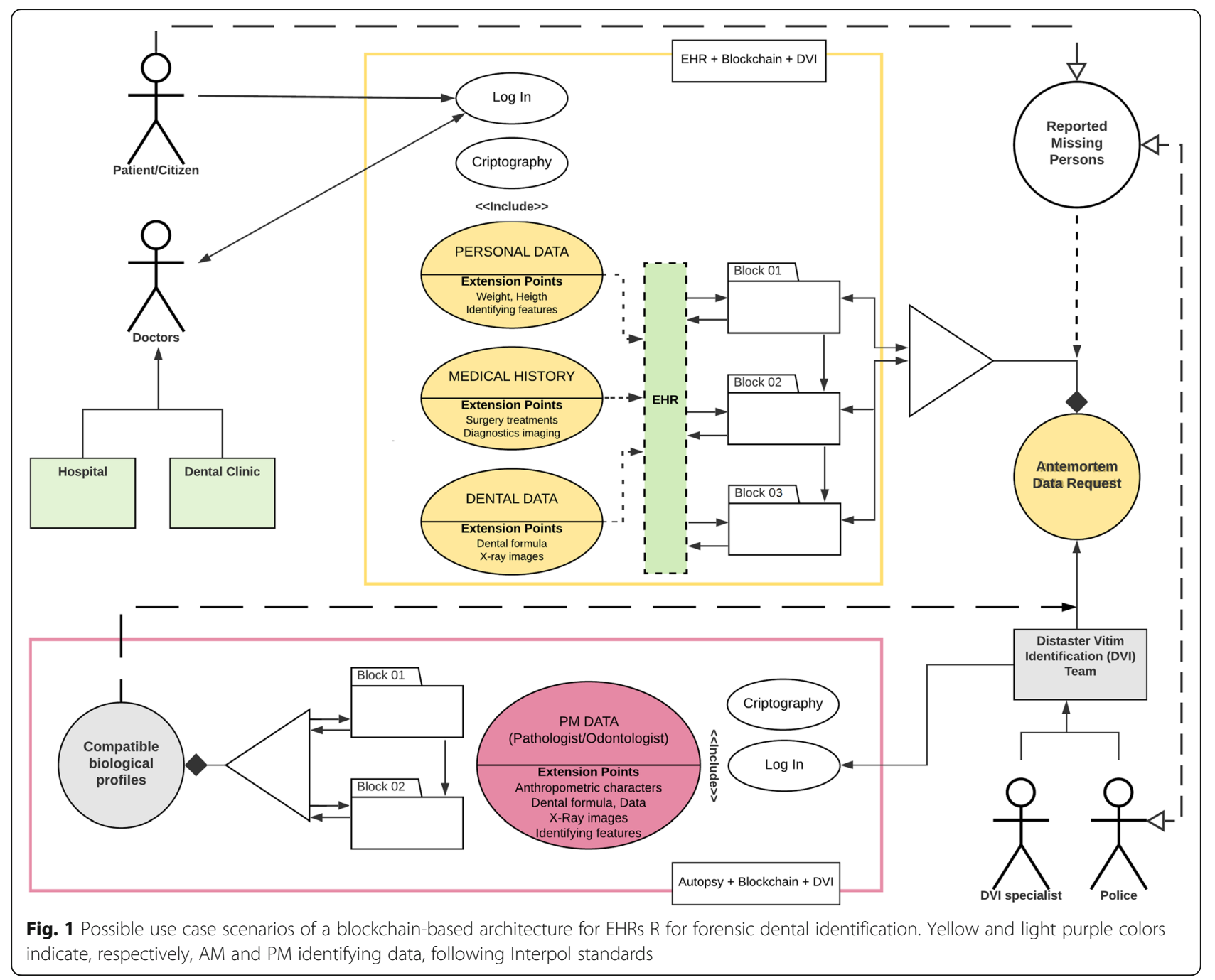

Therefore, there is no record of any blockchain-based solutions to date for data sharing and information interoperability for the purpose of human identification. To test this hypothesis, one should implement a forensic scientists-accessed component in a blockchain solution within the health care setting. Independently from the informatic solutions, which goes beyond the scope of this article, a forensic chain should be implemented to allow forensic DVI specialists and trusted parties (e.g., missing persons organization, research universities institutions, and governmental agencies) to add, modify, and review $\mathrm{AM}$ and PM data information of missing persons and unidentified human remains in a permissioned blockchain. These parties would have the authority to interface with the EHRs blockchain bases, thus creating an interoperability and integrations of those health data blocks with information (between patients and health care parties) potentially useful for a human identification process. Patient health record could also be implemented with the use of technologies such as wearable computing, IoT, and artificial intelligence already applied to health, which could serve as a further forensic use such as the management of the injured and victims of a mass disaster or the search and rescue of missing persons.

\section{Implications of the hypothesis}

The human identification process relies on numerous identifying data, personal features, and medical/dental information. Notably, the use of dental data can facilitate this process in a speedy, timely, and low-cost manner, when compared with DNA. Although it is likely that most national justice systems will develop and improve their criminal database with fingerprints and DNA samples, dental data will remain one of the fundamental primary identifiers of unidentified human remains, as it allows the assessment of a preliminary generic biological profile (e.g., sex, age, geographical origin, and lifestyle) 
and a definitive identification when AM dental data becomes available. This is the reason why PM dental data should always be collected in order to establish a preliminary profile of the unidentified persons, without which it would not be possible to narrow the search of compatible missing persons candidates and achieve a positive ID.

The utilization of advanced technologies, including blockchain technology and artificial intelligence both in healthcare and forensic sciences, can help achieve an automated archiving system, building trustworthy, secure, and holistic ecosystems; protecting against data breaches; preventing redundancies and inconsistencies; and assisting in reducing medical errors (Han et al. 2016) by optimizing resources and accessing to citizens' medical histories, thus speeding up the forensic human identification process, especially in those caseworks where the nationalities of victims is unknown. It would be inconceivable to keep the healthcare sector and related medical-dental data apart from a forensic use following the need of identifying human remains. An integrated forensic chain with a blockchain architecture would make this data available to all healthcare professionals as forensic scientists, with different levels of authorization and access. No less important is the role of the patient-citizen in the collection of personal data which would include identifying features (secondary identifiers), such as weight, height, and photographs showing frontal teeth, which will be available when reporting a missing person. Each year in the USA, over 600,000 individuals go missing, and 4400 are the estimate of unidentified bodies recovered (NamUs 2020). Enhancing the human identification process will definitely reduce the occurrence of cold cases, and therefore also respecting also the human rights of the dead to have a name and an identity (Nuzzolese 2012; Sumathipala et al. 2006)

A forensic chain solution will have to face challenges of data security, data block storage, and forensicadministrative data access as well as tighter jurisdictionspecific data protection laws and regulations, like the General Data Protection Regulation which is considered the toughest privacy and security law applied today (GDPR 2019).

\section{Conclusions}

A blockchain-based architecture for electronic health records of patients, integrated with a structured and interoperable design for human identification could revolutionize this process worldwide, improving management of missing persons data, dental data repositories of living people, postmortem dental data repositories of unidentified human remains of unknown nationality, and contribute to the preliminary comparison of biological profiles of compatible individuals, thus contributing to the definitive identification. Blockchain technology, and a forensic chain, is a potent viable solution for patient-, doctor-, and forensic scientist-centered access, with universal interoperability for managing health and dental data for both medical as forensic human identification use.

\section{Abbreviations \\ AM: Antemortem; PM: Postmortem; ID: Identification; DVI: Disaster victim identification; EHRs: Electronic health records; UML: Unified modeling language}

\section{Acknowledgements \\ Not applicable.}

Author's contributions

The author(s) read and approved the final manuscript.

Funding

This article received no funding.

Availability of data and materials

Not applicable.

Ethics approval and consent to participate

Ethical approval is not applicable for this study.

Consent for publication

Given by the author.

\section{Competing interests}

The author declares that there are no competing interests.

Received: 20 June 2020 Accepted: 27 September 2020

Published online: 06 October 2020

\section{References}

Al-Megren S, Alsalamah S, Altoaimy L, Alsalamah H, Soltanisehat L, Almutairi E, Pentland A (2018) Blockchain use cases in digital sectors: a review of the literature. In: The 2018 IEEE International Conference on Blockchain (Blockchain-2018). July 30- August 03, 2018, Halifax, Canada, pp 1417-1424. https://doi.org/10.1109/Cybermatics 2018.2018.00242

Alsalamah S, Nuzzolese E (2020) Promising blockchain technology applications and use cases designs for the identification of multinational victims of mass disasters. Front Blockchain 3:34. https://doi.org/10.3389/fbloc.2020.00034

Beinke JH, Fitte C, Teuteberg F (2019) Towards a stakeholder-oriented blockchain-based architecture for electronic health records: design science research study. J Med Internet Res 21(10):e13585. https://doi.org/10.2196/ 13585

Han JE, Rabinovich M, Abraham P, Satyanarayana P, Liao TV, Udoji TN et al (2016) Effect of electronic health record implamentation in critical care on survival and medication errors. Am J Med Sci 351(6):576.581

Häyrinen K, Saranto K, Nykänen P (2008) Definition, structure, content, use and impacts of electronic health records: a review of the research literature. Int J Med Inform 77(5):291-304. https://doi.org/10.1016/j.jimedinf.2007.09.001

Hofmeister U, Martin SS, Villalobos C, Padilla J, Finegan O (2017) The ICRC AM/PM Database: challenges in forensic data management in the humanitarian sphere. Forensic Sci Int 279:1-7. https://doi.org/10.1016/j.forsciint.2017.07.022

Hylock RH, Zeng X (2019) A blockchain framework for patient centered health records and exchange (HealthChain); evaluation and proof-of-concept study. J Med Internet Res 21(8):e13592. https://doi.org/10.2196/13592

INTERPOL (2018) Disaster victim identification guide. INTERPOL, Lyon https:// www.interpol.int/en/content/download/589/file/18Y1344\%20E\%20DVI_Guide. pdf. Accessed 6 Feb 2020

Kruse CS, Stein A, Thomas H, Kaur H (2018) The use of electronic health records to support population health: a systematic review of the literature. J Med Syst 42(11):214. https://doi.org/10.1007/s10916-018-1075-6 
Mayer AH, da Costa CA, Righi R (2019) Electronic health records in a blockchain: a systematic review. Health Inform J. https://doi.org/10.1177/ 1460458219866350

Morgan OW, Tidball-Binz O, Van Alphen D (eds) (2006) Management of dead bodies after disasters: a field manual for first responders. Pan American Health Organisation, Washington DC https://www.icrc.org/en/doc/assets/ files/other/icrc_002_0880.pdf. Accessed 6 June 2020

Nakamoto S (2008) Bitcoin: a peer-to-peer electronic cash system, 2008. https:// bitcoin.org/bitcoin.pdf. Accessed 6 Feb 2020.

National Missing and Unidentified Persons System (NamUs) National Institute of Justice. Available at: https://www.namus.gov/. Accessed 12 June 2020.

Nuzzolese E (2012) Missing people, migrants, identification and human rights. J Forensic Odontostomatol 30(Suppl 1):47-59 http://www.iofos.eu/Journals/ JFOS\%20sup1_Nov12/IDEALS\%206-96.pdf. Accessed 6 June 2020

Nuzzolese E, Lupariello F, Di Vella G (2018) Selfie identification app as a forensic tool for missing and unidentified persons. J Forensic Dent Sci 10(2):75-78 http://www.jfds.org/text.asp?2018/10/2/75/249649. Accessed 6 July 2020

Schuller-Götzburg P, Suchanek J (2007) Forensic odontologists successfully identify tsunami victims in Phuket, Thailand. Forensic Sci Int 171:204-207

Senn RD, Weems RA (2013) Manual of forensic odontology, 5th edn. CRC Press, Boca Raton

Silver WE, Souviron RR (2009) Dental autopsy. CRC Press, Boca Raton

Sumathipala A, Siribaddana S, Perera C (2006) Management of dead bodies as a component of psychosocial interventions after the tsunami: a view from Sri Lanka. Int Rev Psychiatry (Abingdon, England) 18(3). https://doi.org/10.1080/ 09540260600656100

The General Data Protection Regulation GDPR (2019) https://gdpr.eu/tag/gdpr/. Accessed 1 Jan 2020

WHO (2018) Severnty-First World Health Assembly, Digital Health, Geneva, Switzerland. https://apps.who.int/gb/ebwha/pdf_files/WHA71/A71_R7-en pdf?ua=1. Accessed 30 Sep 2020

\section{Publisher's Note}

Springer Nature remains neutral with regard to jurisdictional claims in published maps and institutional affiliations.

\section{Submit your manuscript to a SpringerOpen ${ }^{\circ}$ journal and benefit from:}

- Convenient online submission

- Rigorous peer review

- Open access: articles freely available online

- High visibility within the field

- Retaining the copyright to your article

Submit your next manuscript at $\boldsymbol{\nabla}$ springeropen.com 